\title{
The Optimization of Logistics Distribution Route Based on Dijkstra's Algorithm and C-W Savings Algorithm
}

\author{
Dan Ding ${ }^{1,}$, Xin Zou ${ }^{1,2, b}$ \\ ${ }^{1}$ College of Management Science, Chengdu University of Technology, Chengdu 610059, China; \\ ${ }^{2}$ Division of Information Technology, Engineering and the Environment, University of South \\ Australia, Adelaide 5095, Australia. \\ a469619322@qq.com, bouxy011@mymail.unisa.edu.au
}

Keywords: Dijkstra's Algorithm; C-W Savings Algorithm; Distribution Route Optimization

\begin{abstract}
The optimization problem of vehicle distribution routing could be summarized as vehicle routing problem (VRP). The paper simply introduced logistics distribution VRP, established the corresponding optimization model of distribution routing by Dijkstra's Algorithm and Savings Algorithm based on MATLAB software, and verified the effectiveness of the combinational algorithm in accordance with example analysis. According to the results, Dijkstra's Algorithm and Savings Algorithm could optimize logistics distribution routing, effectively reduce distribution mileage and the number of the distributed vehicles, and thus achieve the goal of improving the distribution efficiency, reducing distribution costs, and relieving traffic pressure.
\end{abstract}

\section{Introduction}

As the core function of the logistics system, distribution is directly connected with terminal clients. The performance of the distribution function and its service level directly influence the logistics cost of companies and the satisfaction level of the client for the whole logistics service. The core part of distribution is the process of goods consolidation, sorting and delivery of distribution vehicles. Among this, the reasonable optimization of the distribution routes for the vehicles is significant for the speed, cost, and efficiency of the whole logistics transportation. Because that the transportation cost includes most cost of the logistics center and the urban transportation grows crowded in recent years, the significance of optimizing the route of the distribution vehicles is underpinned (Bardi et al., 2002). Logistics distribution centers play an important role in the goods transportation, aiming to reduce the transportation cost effectively. Therefore, the route of the distribution vehicles and the schedule planning are very important operation decisions and normally they are a kind of vehicle routing problem (VRP).

\section{Introduction to Logistics Distribution VRP}

How to distribute the goods from the manufacturing place or the distributing center to the market effectively is an issue to which the academic circle attaches great importance, such as travelling salesman problem (TSP) and vehicle routing problem (VRP). VRP is the extension of TSP and it was firstly raised by Dantzig and Ramser in 1959. It is a set of the heuristic method using the linear programming method. The basic goal of VPR is to find the minimal cost routing while meeting the requirements of all clients. Because of the feature of NP-hard in VRP (Lenstra and Kan, 1981), the complexity of the solution grows exponentially with the increasing requirement knots. Therefore, solving large problems usually needs to cost very long time so as to get the optimal solution. To reflect the real conditions and actually utilize VRP in the traffic networks, many scholars add various limitations to it, such as limitation of carrying capacity and time window limitation. The types of the problem turn from the single station to multi-station; the single car type turns to the mixed car type, the traffic flow of the network turns from the static to the dynamic, and the off-line solution turns to on-line solution. The application and the solution algorithm of VRP have been applied to the relative problems of the city logistics (Barceló et al., 2007). The city logistics refers 
to any transportation activity in the city in general and it considers the problems caused during the transportation, such as the transportation jam, energy consumption, and economic benefit (Taniguchi et al., 2001).

The difference between VRP and TSP lies in: VRP increases the more realistic limitations in terms of practice of time, distance and vehicle capacity with hope for finding out the optimal distribution route which both meets the distribution requirement and limitations. Therefore, its solution may include various routes (Ghiani et al., 2004). Normally, the vehicle routing problem has the following features:

(1) Having known the distribution network and the requirement of different distribution spots;

(2) Having known the types and number of the distribution vehicles;

(3) Having known the requirements of the terminal client and the requirements for the distribution conditions;

(4) Under the relative limitations of the known routes, looking for the distribution route schedules of the minimum total cost, the shortest distribution time or the minimum distribution vehicles.

\section{Optimization methods for logistics distribution routes}

In past times, the study on VRP mainly focused on the heuristic solution, most of which were corrected from the heuristic solution of TSP. There are mainly three following methods:

(1) Route construction methods

In the route construction methods, each two client will be connected till all clients are designated to one certain vehicle route. There are mainly two solutions: the first is to use the savings criterion to merger the existing routes and the second is to use the insertion cost to add single client to the vehicle route. C-W Savings Algorithm (Clarke and Wright, 1964) is the best-known heuristic solution for solving VRP, including two kinds which are parallel and sequential.

(2) Route improvement methods

The route improvement methods begin with an initial feasible solution, chooses some lines to exchange, ensure that it is feasible solution after exchange and it can reduce the cost. This method originates from the heuristic solution proposed by Lin for the solution of TSP (Lin, 1965). Gaskell, Christofides and Eilon corrected this solution and applied it into VRP (Gaskell, 1967; Christofidesand Eilon, 1969).

(3) Two-stage methods

In the first stage, the client at first is designated to the vehicles without the consideration for the sequence of route. In the second stage, the heuristic solution of TSP is used to plan the routes of vehicles. The two-stage method (Fisher and Jaikumar, 1981) did not use the geometric method to decide the grouping in the first stage but to turn the problem into the assignment problem to find the solution.

The VRP composite route optimization method used in this paper is divided into two stages: in the first stage, Dijkstra's Algorithm is used to calculate the shortest route and distance between knots; in the second stage, based on the idea of joint distribution, Clarke and Wright's Savings Algorithm is used to optimize the distribution route. The steps of solution for two algorithms are shown as the follows:

\section{Dijkstra's Algorithm}

Dijkstra's Algorithm was put forward by the Dutch computer scientist E. W. Dijkstra in 1959. It solves the problem of the shortest distance from a single starting point to other points in the directed graph and it is a method which calculates the shortest routes after finishing the weighted consideration.

The calculating steps of Dijkstra's Algorithm are shown as the follows:

Step 1: Divide all the knots in the graph into two sets of $S$ and $U$ : "the visited knots set" are put in $S$ with the original condition of null set; "the not-yet-visited knots set" are put in $U$ with the original condition of all distribution sites set.

Step 2: Change the starting point $O$ (normally the logistics center) as a permanent label and move 
from $U$ to $S$. Set the starting point's $P_{(O)}=N U L L$, the distant travelling cost of starting point $L_{(O)}=0$, setting $i=O$; The distant travelling cost of all other knots $j: L_{(j)}=\infty$. Thereinto, $P_{(i)}$ is the up-stream knot of knot $i$ and $\Gamma(i)$ is the collection of all $i$.

Step 3: Update all the knots which is labeled as temporary in $\Gamma(i): L_{(j)}=\min \left[L_{(j)}, L_{(i)}+w(i, j)\right]$, if $L_{(i)}+w(i, j)<L_{(j)}$, then $P_{(j)}=i$.

Step 4: Choose the smallest knot $j$ of $L_{(j)}$ from $U$.

Step 5: Set knot $j$ as the permanent label, move it from set $U$ to set $S$ and let $i=j$.

Step 6: If $i=D$, then it is the shortest distance from the starting site $O$ to distribution site $D, L_{(D)}$ is the minimum travelling cost; if $i \neq D$, return to Step 2 to continue the calculation.

The advantage of Dijkstra's Algorithm is that it does not need to go through all knots so as to find the shortest route. If the shortest route has found out the target distribution site, the distribution routes to the distribution site will necessarily spend more time than this route and the sub-path of this shortest route will necessarily become the shortest route. However, even though Dijkstra's Algorithm can get the optimal solution, it will waste a lot of time for searching for the unnecessary directions when the scale of the traffic network is large. For example, when the distribution site is located in the southeast direction of the starting point, Dijkstra's Algorithm will search for all the possible routes in all directions, including the northwest or other directions.

\section{C-W Savings Algorithm}

Chengdu Y Cold-Chain Warehouse \& Logistics Public Limited Company is a commercial logistics company which integrates the agricultural and sideline products' preservation, cold storage, refrigeration, distribution processing, city food distribution, and estate development into one. The subordinate agricultural product cold chain logistics center of $\mathrm{Y}$ Company is located in the Qingbaijiang large bulk-cargo logistics park in Chengdu. The park is part of the western railway logistics hub planned and established by the Sichuan provincial government. The project takes up 34.667 hectares, including the supporting facility of low-temperature cold store with the total capacity of 300,000 tons, distribution logistics center of 160,000 square meters, integrated warehouse (air-conditioned cold store, high temperature cold store, and normal store) of 100,000 square meters, and special line for railway. At the appointed time, it will become the largest collecting and distribution center for the frozen livestock and poultry product, aquatic product, dried food, non-staple food, and vegetables and fruits in the southwest.

Through the visit and the investigation, the location and distances of the cold-chain warehouse \& distribution center of Y Company and the distribution sites are shown in the Fig. 1 in detail. Circle 0 represents the cold-chain warehouse \& distribution center. Circle 1 to 11 represent the numbers of the distribution sites. The values between the circles are the distance between the distribution sites. Because the freight rate in the covering range of the warehouse \& distribution center is set, the influence of the freight rate will not be considered. Besides, the distribution vehicles of the warehouse \& distribution center are enough and all of them are the box-type refrigerating car with the load capacity of 3 tons and they have sufficient transport capacity. It is aimed at optimizing the distribution routes of 11 distribution sites. Dijkstra's Algorithm and C-W Savings Algorithm are used to optimize the distribution routes of the warehouse \& distribution center with the optimization objective of minimizing the freight turnover $(\mathrm{t} \cdot \mathrm{km})$. 


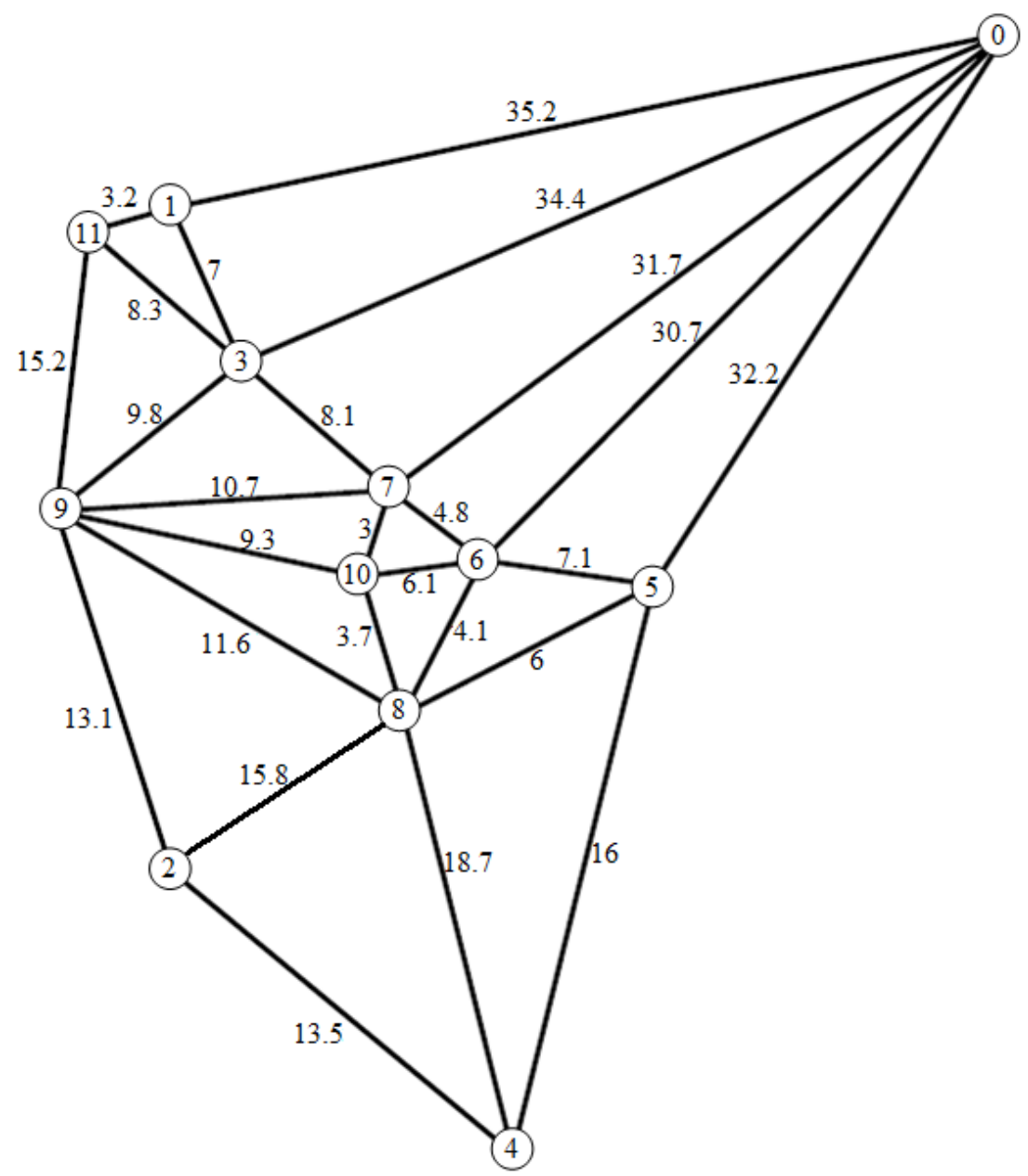

Fig. 1. Relative position and distances of the warehouse \& distribution center and distribution sites

\section{Utilization of Dijkstra's Algorithm to calculate the shortest route}

Due to the huge amount of the knots and the difficulty for calculation, this paper utilizes MATLAB R2016a as the auxiliary to solve the shortest route and distance between knots. Input the procedure code:

(1) Define the function

function $[$ distance path] $=\operatorname{Dijk}(\mathrm{W}, \mathrm{st}, \mathrm{e})$

\% W (Weight matrix), st (Starting search point), e (Terminal search point)

$\mathrm{n}=$ length(W); \% Number of Nodes

$\mathrm{D}=\mathrm{W}(\mathrm{st}, \mathrm{:})$;

visit $=$ ones $(1, \mathrm{n})$; visit(st) $=0$;

parent $=$ zeros $(1, \mathrm{n}) ; \%$ Record the previous node of each node.

path $=[]$;

for $\mathrm{i}=1: \mathrm{n}-1$

$$
\text { temp }=[]
$$

\% From the starting point, find the next point of the shortest distance. Don't repeat the previous track. Set up the visit to determine whether to visit the node.

$$
\begin{aligned}
& \begin{array}{l}
\text { for } \mathrm{j}=1: \mathrm{n} \\
\text { if visit(j) } \\
\text { temp }=[\text { temp } \mathrm{D}(\mathrm{j})] \text {; }
\end{array} \\
& \text { else } \\
& \text { end }
\end{aligned}
$$


end

[value,index] = min(temp);

visit(index) $=0$;

\% Updating: if the index node is passed through, the length of path from the starting point to each node will be smaller, then update. Record the front node to facilitate the later back tracking. for $\mathrm{k}=1: \mathrm{n}$

if $\mathrm{D}(\mathrm{k})>\mathrm{D}$ (index) $+\mathrm{W}($ index, $\mathrm{k})$

$\mathrm{D}(\mathrm{k})=\mathrm{D}($ index $)+\mathrm{W}($ index, $\mathrm{k})$;

end

parent $(\mathrm{k})=$ index;

end

distance $=\mathrm{D}(\mathrm{e}) ; \%$ The shortest distance

\% Backtracking method: to find search path from the end to the front.

$\mathrm{t}=\mathrm{e}$;

while $\mathrm{t} \sim=$ st $\& \& \mathrm{t}>0$

path $=[\mathrm{t}, \mathrm{path}]$;

$\mathrm{p}=$ parent $(\mathrm{t}) ; \mathrm{t}=\mathrm{p}$;

end

path $=[$ st,path]; \% The shortest route

end

(2) Build the topological graph

$\mathrm{W}=[0$ 0 35.2 inf 34.4 inf 32.2 30.7 31.7 inf inf inf inf;

35.20 inf 7 inf inf inf inf inf inf inf 3.2;

inf inf 0 inf $13.5 \mathrm{inf}$ inf inf $15.813 .1 \mathrm{inf}$ inf;

34.47 inf 0 inf inf inf 8.1 inf 9.8 inf 8.3;

inf inf 13.5 inf 016 inf inf 18.7 inf inf inf;

32.2 inf inf inf 1607.1 inf 6 inf inf inf;

30.7 inf inf inf inf 7.1 04.84 .1 inf 6.1 inf;

$31.7 \mathrm{inf}$ inf $8.1 \mathrm{inf}$ inf $4.80 \mathrm{inf} 10.73 \mathrm{inf} ;$

inf inf 15.8 inf 18.764 .1 inf 011.63 .7 inf;

inf inf 13.1 9.8 inf inf inf 10.711 .609 .3 15.2;

inf inf inf inf inf inf 6.1 33.79 .30 inf;

inf $3.2 \mathrm{inf} 8.3 \mathrm{inf} \inf \inf \inf \inf 15.2 \mathrm{inf} 0$ ];

for $i=1: 12$

for $j=1: 12$

[distance,path]=Dijk(W,i,j);

fprintf('The shortest route from point \%d to point \%d is:',i-1,j-1);

path-1

format long g

fprintf('The shortest distance of the route from point \%d to point \%d is ',i-1,j-1);

format long g

distance

end

end

Arrange the output of MATLAB R2016a so that the shortest routes and distances of all the knots are shown as Table 1. 
Table 1. Computational results by MATLAB

\begin{tabular}{|c|c|}
\hline Starting point & The shortest route and distance \\
\hline 0 & $\begin{array}{l}0 \rightarrow 0=0,0 \rightarrow 1=35.2,0 \rightarrow 6 \rightarrow 8 \rightarrow 2=50.6,0 \rightarrow 3=34.4,0 \rightarrow 5 \rightarrow 4=48.2,0 \rightarrow 5=32.2, \\
0 \rightarrow 6=30.7,0 \rightarrow 7=31.7,0 \rightarrow 6 \rightarrow 8=34.8,0 \rightarrow 7 \rightarrow 9=42.4,0 \rightarrow 7 \rightarrow 10=34.7,0 \rightarrow 1 \rightarrow 11=38.4\end{array}$ \\
\hline 1 & $\begin{array}{l}1 \rightarrow 0=35.2,1 \rightarrow 1=0,1 \rightarrow 3 \rightarrow 9 \rightarrow 2=29.9,1 \rightarrow 3=7,1 \rightarrow 3 \rightarrow 7 \rightarrow 10 \rightarrow 8 \rightarrow 4=40.5, \\
1 \rightarrow 3 \rightarrow 7 \rightarrow 6 \rightarrow 5=27,1 \rightarrow 3 \rightarrow 7 \rightarrow 6=19.9,1 \rightarrow 3 \rightarrow 7=15.1,1 \rightarrow 3 \rightarrow 7 \rightarrow 10 \rightarrow 8=21.8 \\
1 \rightarrow 3 \rightarrow 9=16.8,1 \rightarrow 3 \rightarrow 7 \rightarrow 10=18.1,1 \rightarrow 11=3.2\end{array}$ \\
\hline 2 & $\begin{array}{l}2 \rightarrow 8 \rightarrow 6 \rightarrow 0=50.6,2 \rightarrow 9 \rightarrow 3 \rightarrow 1=29.9,2 \rightarrow 2=0,2 \rightarrow 9 \rightarrow 3=22.9,2 \rightarrow 4=13.5,2 \rightarrow 8 \rightarrow 5=21.8, \\
2 \rightarrow 8 \rightarrow 6=19.9,2 \rightarrow 8 \rightarrow 10 \rightarrow 7=22.5,2 \rightarrow 8=15.8,2 \rightarrow 9=13.1,2 \rightarrow 8 \rightarrow 10=19.5, \\
2 \rightarrow 9 \rightarrow 11=28.3\end{array}$ \\
\hline 3 & $\begin{array}{l}3 \rightarrow 0=34.4,3 \rightarrow 1=7,3 \rightarrow 9 \rightarrow 2=22.9,3 \rightarrow 3=0,3 \rightarrow 7 \rightarrow 10 \rightarrow 8 \rightarrow 4=33.5,3 \rightarrow 7 \rightarrow 6 \rightarrow 5=20, \\
3 \rightarrow 7 \rightarrow 6=12.9,3 \rightarrow 7=8.1,3 \rightarrow 7 \rightarrow 10 \rightarrow 8=14.8,3 \rightarrow 9=9.8,3 \rightarrow 7 \rightarrow 10=11.1,3 \rightarrow 11=8.3\end{array}$ \\
\hline 4 & $\begin{array}{l}4 \rightarrow 5 \rightarrow 0=48.2,4 \rightarrow 8 \rightarrow 10 \rightarrow 7 \rightarrow 3 \rightarrow 1=40.5,4 \rightarrow 2=13.5,4 \rightarrow 8 \rightarrow 10 \rightarrow 7 \rightarrow 3=33.5 \text { 4 } \rightarrow 4=0, \\
4 \rightarrow 5=16,4 \rightarrow 8 \rightarrow 6=22.8,4 \rightarrow 8 \rightarrow 10 \rightarrow 7=25.4,4 \rightarrow 8=18.7,4 \rightarrow 2 \rightarrow 9=26.6,4 \rightarrow 8 \rightarrow 10=22.4, \\
4 \rightarrow 2 \rightarrow 9 \rightarrow 11=41.8\end{array}$ \\
\hline 5 & $\begin{array}{l}5 \rightarrow 0=32.2,5 \rightarrow 6 \rightarrow 7 \rightarrow 3 \rightarrow 1=27,5 \rightarrow 8 \rightarrow 2=21.8,5 \rightarrow 6 \rightarrow 7 \rightarrow 3=20,5 \rightarrow 4=16,5 \rightarrow 5=0, \\
5 \rightarrow 6=7.1,5 \rightarrow 6 \rightarrow 7=11.9,5 \rightarrow 8=6,5 \rightarrow 8 \rightarrow 9=17.6,5 \rightarrow 8 \rightarrow 10=9.7,5 \rightarrow 6 \rightarrow 7 \rightarrow 3 \rightarrow 11=28.3\end{array}$ \\
\hline 6 & $\begin{array}{l}6 \rightarrow 0=30.7,6 \rightarrow 7 \rightarrow 3 \rightarrow 1=19.9,6 \rightarrow 8 \rightarrow 2=19.9,6 \rightarrow 7 \rightarrow 3=12.9,6 \rightarrow 8 \rightarrow 4=22.8,6 \rightarrow 5=7.1, \\
6 \rightarrow 6=0,6 \rightarrow 7=4.8,6 \rightarrow 8=4.1,6 \rightarrow 10 \rightarrow 9=15.4,6 \rightarrow 10=6.1,6 \rightarrow 7 \rightarrow 3 \rightarrow 11=21.2\end{array}$ \\
\hline 7 & $\begin{array}{l}7 \rightarrow 0=31.7,7 \rightarrow 3 \rightarrow 1=15.1,7 \rightarrow 10 \rightarrow 8 \rightarrow 2=22.5,7 \rightarrow 3=8.1,7 \rightarrow 10 \rightarrow 8 \rightarrow 4=25.4 \\
7 \rightarrow 6 \rightarrow 5=11.9,7 \rightarrow 6=4.8,7 \rightarrow 7=0,7 \rightarrow 10 \rightarrow 8=6.7,7 \rightarrow 9=10.7,7 \rightarrow 10=3,7 \rightarrow 3 \rightarrow 11=16.4\end{array}$ \\
\hline 8 & $\begin{array}{l}8 \rightarrow 6 \rightarrow 0=34.8,8 \rightarrow 10 \rightarrow 7 \rightarrow 3 \rightarrow 1=21.8,8 \rightarrow 2=15.8,8 \rightarrow 10 \rightarrow 7 \rightarrow 3=14.8,8 \rightarrow 4=18.7 \\
8 \rightarrow 5=6,8 \rightarrow 6=4.1,8 \rightarrow 10 \rightarrow 7=6.7,8 \rightarrow 8=0,8 \rightarrow 9=11.6,8 \rightarrow 10=3.7 \\
8 \rightarrow 10 \rightarrow 7 \rightarrow 3 \rightarrow 11=23.1\end{array}$ \\
\hline 9 & $\begin{array}{l}9 \rightarrow 7 \rightarrow 0=42.4,9 \rightarrow 3 \rightarrow 1=16.8,9 \rightarrow 2=13.1,9 \rightarrow 3=9.8,9 \rightarrow 2 \rightarrow 4=26.6,9 \rightarrow 8 \rightarrow 5=17.6, \\
9 \rightarrow 10 \rightarrow 6=15.4,9 \rightarrow 7=10.7,9 \rightarrow 8=11.6,9 \rightarrow 9=0,9 \rightarrow 10=9.3,9 \rightarrow 11=15.2\end{array}$ \\
\hline 10 & $\begin{array}{l}10 \rightarrow 7 \rightarrow 0=34.7,10 \rightarrow 7 \rightarrow 3 \rightarrow 1=18.1,10 \rightarrow 8 \rightarrow 2=19.5,10 \rightarrow 7 \rightarrow 3=11.1,10 \rightarrow 8 \rightarrow 4=22.4, \\
10 \rightarrow 8 \rightarrow 5=9.7,10 \rightarrow 6=6.1,10 \rightarrow 7=3,10 \rightarrow 8=3.7,10 \rightarrow 9=9.3,10 \rightarrow 10=0, \\
10 \rightarrow 7 \rightarrow 3 \rightarrow 11=19.4\end{array}$ \\
\hline 11 & $\begin{array}{l}11 \rightarrow 1 \rightarrow 0=38.4,11 \rightarrow 1=3.2,11 \rightarrow 9 \rightarrow 2=28.3,11 \rightarrow 3=8.3,11 \rightarrow 3 \rightarrow 7 \rightarrow 10 \rightarrow 8 \rightarrow 4=41.8, \\
11 \rightarrow 3 \rightarrow 7 \rightarrow 6 \rightarrow 5=28.3,11 \rightarrow 3 \rightarrow 7 \rightarrow 6=21.2,11 \rightarrow 3 \rightarrow 7=16.4,11 \rightarrow 3 \rightarrow 7 \rightarrow 10 \rightarrow 8=23.1 \\
11 \rightarrow 9=15.2,11 \rightarrow 3 \rightarrow 7 \rightarrow 10=19.4,11 \rightarrow 11=0\end{array}$ \\
\hline
\end{tabular}

According to Table 1, the shortest distances of all the knots can be organized as Table 2 .

Table 2. The shortest distances of each node $\mathrm{km}$

\begin{tabular}{|c|c|c|c|c|c|c|c|c|c|c|c|c|}
\hline & 0 & 1 & 2 & 3 & 4 & 5 & 6 & 7 & 8 & 9 & 10 & 11 \\
\hline 0 & 0 & 35.2 & 50.6 & 34.4 & 48.2 & 32.2 & 30.7 & 31.7 & 34.8 & 42.4 & 34.7 & 38.4 \\
\hline 1 & & 0 & 29.9 & 7 & 40.5 & 27 & 19.9 & 15.1 & 21.8 & 16.8 & 18.1 & 3.2 \\
\hline 2 & & & 0 & 22.9 & 13.5 & 21.8 & 19.9 & 22.5 & 15.8 & 13.1 & 19.5 & 28.3 \\
\hline 3 & & & & 0 & 33.5 & 20 & 12.9 & 8.1 & 14.8 & 9.8 & 11.1 & 8.3 \\
\hline 4 & & & & & 0 & 16 & 22.8 & 25.4 & 18.7 & 26.6 & 22.4 & 41.8 \\
\hline 5 & & & & & & 0 & 7.1 & 11.9 & 6 & 17.6 & 9.7 & 28.3 \\
\hline 6 & & & & & & & 0 & 4.8 & 4.1 & 15.4 & 6.1 & 21.2 \\
\hline 7 & & & & & & & & 0 & 6.7 & 10.7 & 3 & 16.4 \\
\hline 8 & & & & & & & & & 0 & 11.6 & 3.7 & 23.1 \\
\hline 9 & & & & & & & & & & 0 & 9.3 & 15.2 \\
\hline 10 & & & & & & & & & & & 0 & 19.4 \\
\hline 11 & & & & & & & & & & & & 0 \\
\hline
\end{tabular}

\section{Utilization of C-W Savings Algorithm to optimize the distribution routes}

Calculate the saved distance between distribution sites according to the savings value formula $S_{i j}=D_{0 i}+D_{0 j}-D_{i j}$ and rank the results in descending order so as to merger the one which has larger saved distance from the cold-chain warehouse \& distribution center to two distribution sites. The ranking results are shown as Table 3. 
Table 3. Ranked list of saved mileages $\mathrm{km}$

\begin{tabular}{ccc|ccc|ccc}
\hline $\begin{array}{c}\text { Serial } \\
\text { Number }\end{array}$ & Route & $\begin{array}{c}\text { Saved } \\
\text { Mileage }\end{array}$ & $\begin{array}{c}\text { Serial } \\
\text { Number }\end{array}$ & Route & $\begin{array}{c}\text { Saved } \\
\text { Mileage }\end{array}$ & $\begin{array}{c}\text { Serial } \\
\text { Number }\end{array}$ & Route & $\begin{array}{c}\text { Saved } \\
\text { Mileage }\end{array}$ \\
\hline 1 & $2 \rightarrow 4$ & 85.3 & 20 & $6 \rightarrow 8$ & 61.4 & 38 & $4 \rightarrow 7$ & 54.5 \\
2 & $2 \rightarrow 9$ & 79.9 & 21 & $2 \rightarrow 5$ & 61 & 39 & $3 \rightarrow 8$ & 54.4 \\
3 & $1 \rightarrow 11$ & 70.4 & 22 & $5 \rightarrow 8$ & 61 & 40 & $7 \rightarrow 11$ & 53.7 \\
4 & $2 \rightarrow 8$ & 69.6 & 23 & $1 \rightarrow 9$ & 60.8 & 41 & $10 \rightarrow 11$ & 53.7 \\
5 & $9 \rightarrow 10$ & 67.8 & 24 & $2 \rightarrow 11$ & 60.7 & 42 & $3 \rightarrow 6$ & 52.2 \\
6 & $3 \rightarrow 9$ & 67 & 25 & $4 \rightarrow 10$ & 60.5 & 43 & $5 \rightarrow 7$ & 52 \\
7 & $2 \rightarrow 10$ & 65.8 & 26 & $2 \rightarrow 7$ & 59.8 & 44 & $1 \rightarrow 7$ & 51.8 \\
8 & $8 \rightarrow 10$ & 65.8 & 27 & $7 \rightarrow 8$ & 59.8 & 45 & $1 \rightarrow 10$ & 51.8 \\
9 & $8 \rightarrow 9$ & 65.6 & 28 & $6 \rightarrow 10$ & 59.3 & 46 & $8 \rightarrow 11$ & 50.1 \\
10 & $9 \rightarrow 11$ & 65.6 & 29 & $3 \rightarrow 7$ & 58 & 47 & $3 \rightarrow 4$ & 49.1 \\
11 & $3 \rightarrow 11$ & 64.5 & 30 & $3 \rightarrow 10$ & 58 & 48 & $1 \rightarrow 8$ & 48.2 \\
12 & $4 \rightarrow 5$ & 64.4 & 31 & $6 \rightarrow 9$ & 57.7 & 49 & $6 \rightarrow 11$ & 47.9 \\
13 & $4 \rightarrow 8$ & 64.3 & 32 & $6 \rightarrow 7$ & 57.6 & 50 & $3 \rightarrow 5$ & 46.6 \\
14 & $4 \rightarrow 9$ & 64 & 33 & $5 \rightarrow 10$ & 57.2 & 51 & $1 \rightarrow 6$ & 46 \\
15 & $7 \rightarrow 9$ & 63.4 & 34 & $5 \rightarrow 9$ & 57 & 52 & $4 \rightarrow 11$ & 44.8 \\
16 & $7 \rightarrow 10$ & 63.4 & 35 & $4 \rightarrow 6$ & 56.1 & 53 & $1 \rightarrow 4$ & 42.9 \\
17 & $1 \rightarrow 3$ & 62.6 & 36 & $1 \rightarrow 2$ & 55.9 & 54 & $5 \rightarrow 11$ & 42.3 \\
18 & $2 \rightarrow 3$ & 62.1 & 37 & $5 \rightarrow 6$ & 55.8 & 55 & $1 \rightarrow 5$ & 40.4 \\
19 & $2 \rightarrow 6$ & 61.4 & & & & & & \\
\hline
\end{tabular}

According to the logistics distribution requirement of the cold-chain warehouse \& distribution center of Y Company and the need to ensure the freshness and safety of the fresh agricultural products, the warehouse \& distribution center needs to distribute products for the distribution sites (1 11) everyday. The daily requirements of various distribution sites are shown as Table 4 .

Because the big difference of the daily demand of various distribution sites, some distribution sites need to use lots of refrigerating cars to distribute because of the huge demand. While some distribution sites has smaller distribution demand and the distribution products cannot fill the car so the following distribution rules are regulated so as to better use the refrigerating cars and increase the loading rate:

(1) As for the distribution site while has the average daily demand more than the full capacity of the single car (3t), the goods which meet the requirements for carload will be distributed to and from the warehouse \& distribution center and the distribution sites by the distribution cars and the goods which do not meet the requirement for carload and the goods of other distribution sites will be distributed together.

(2) As for the distribution site which has the average daily demand less than the full capacity of the single car (3t), the goods and the goods of other distribution sites will be distributed together.

Table 4. Average daily demand of each distribution site

\begin{tabular}{ccccc}
\hline $\begin{array}{c}\text { Serial } \\
\text { number }\end{array}$ & Distribution site & $\begin{array}{c}\text { Average } \\
\text { daily } \\
\text { demand } \\
/ \mathrm{t}\end{array}$ & $\begin{array}{c}\text { Average daily demand for } \\
\text { goods to meet a vehicle/t }\end{array}$ & $\begin{array}{c}\text { Average daily demand for } \\
\text { goods not to meet a } \\
\text { vehicle/t }\end{array}$ \\
\hline 1 & Haibawang Food Market & 22.1 & 21 & 1.1 \\
\hline 2 & Baijia Market & 15.3 & 15 & 0.3 \\
\hline 3 & Wal-Mart in Jinniu District & 2.1 & 0 & 2.1 \\
\hline 4 & $\begin{array}{c}\text { Wal-Mart } \\
\text { in Shuangliu District }\end{array}$ & 2.6 & 0 & 0.6 \\
\hline 5 & Wal-Mart in Wuhou District & 3.6 & 3 & 1.4 \\
\hline 6 & $\begin{array}{c}\text { Wal-Mart } \\
\text { in Chenghua District }\end{array}$ & 4.4 & 3 & \\
\hline
\end{tabular}




\begin{tabular}{ccccc}
\hline 7 & $\begin{array}{c}\text { Wal-Mart } \\
\text { in Qingyang District }\end{array}$ & 5 & 3 & 2 \\
\hline 8 & Dadong Commerce and Trade & 7.2 & 6 & 1.2 \\
\hline 9 & Ruixin Restaurant & 4.4 & 3 & 1.4 \\
\hline 10 & Zhongxin Food & 8.4 & 6 & 2.4 \\
\hline 11 & Zhongxin Food & 7.9 & 6 & 1.9 \\
\hline Total & & 83 & 66 & 17 \\
\hline
\end{tabular}

Combine Table 1, Table 3 and Table 4 to determine the distribution route:

Take the distribution site 2 and 4 as the example: because the saved mileage from the distribution 2 to 4 is $85.3 \mathrm{~km}$, the largest in terms of the savings, this route is chosen at first. Distribute the goods of the distribution site 2 which are insufficient for carload $(0.3 t)$ and the goods of the distribution site $4(2.6 \mathrm{t})$ together, with the loading weight of $2.9 \mathrm{t}<3 \mathrm{t}$; at that time, if the distribution sites are increased, the load capacity will exceed 3t. Therefore the route I will be:

$$
0 \rightarrow 6 \rightarrow 8 \rightarrow 2 \rightarrow 4 \rightarrow 5 \rightarrow 0=50.6+13.5+48.2=112.3 \mathrm{~km}
$$

That is to say, send one refrigerating car with the rated load of 3t. The distance is $112.3 \mathrm{~km}$ and the loading weight is 2.9t. As is shown in Fig. 2:

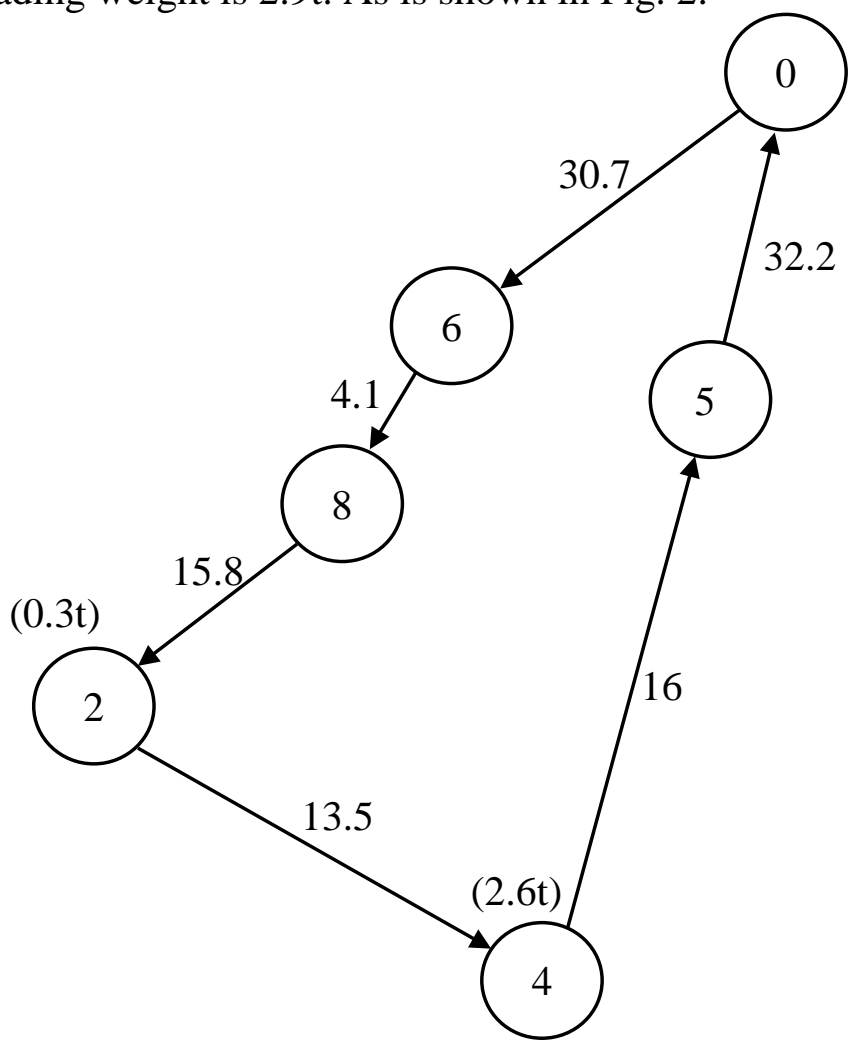

Fig. 2. Diagram of distribution route I

In a similar way, the optimized distribution routes and the distribution plans are shown as Table 5.

Table 5. Optimized distribution scheme

\begin{tabular}{cccccccc}
\hline $\begin{array}{c}\text { Serial } \\
\text { number }\end{array}$ & Route & $\begin{array}{c}\text { Distribution } \\
\text { site }\end{array}$ & $\begin{array}{c}\text { Distribution } \\
\text { mode }\end{array}$ & $\begin{array}{c}\text { Distribution } \\
\text { volume/t }\end{array}$ & $\begin{array}{c}\text { Gross } \\
\text { deadweight/t }\end{array}$ & $\begin{array}{c}\text { Distribution } \\
\text { distance per } \\
\text { vehicle/km }\end{array}$ & $\begin{array}{c}\text { Number of } \\
\text { vehicles }\end{array}$ \\
\hline I & $\begin{array}{c}0 \rightarrow 6 \rightarrow 8 \\
\rightarrow 2 \rightarrow 4 \rightarrow \\
5 \rightarrow 0\end{array}$ & 2 & Joint & 0.3 & 2.9 & 112.3 & 1 \\
\hline II & $\begin{array}{c}0 \rightarrow 6 \rightarrow 8 \\
\rightarrow 2 \rightarrow 8 \rightarrow \\
6 \rightarrow 0\end{array}$ & 2 & Out and back & 15 & 15 & 101.2 & 5 \\
\hline III & $0 \rightarrow 1 \rightarrow 11$ & 1 & Joint & 1.1 & 3 & 76.8 & 1 \\
\hline
\end{tabular}




\begin{tabular}{|c|c|c|c|c|c|c|c|}
\hline & $\rightarrow 1 \rightarrow 0$ & 11 & & 1.9 & & & \\
\hline IV & $0 \rightarrow 1 \rightarrow 0$ & 1 & Out and back & 21 & 21 & 70.4 & 7 \\
\hline V & $\begin{array}{l}0 \rightarrow 1 \rightarrow 11 \\
\quad \rightarrow 1 \rightarrow 0\end{array}$ & 11 & Out and back & 6 & 6 & 76.8 & 2 \\
\hline VI & $\begin{array}{l}0 \rightarrow 7 \rightarrow 9 \\
\rightarrow 10 \rightarrow 7 \\
\quad \rightarrow 0\end{array}$ & $\begin{array}{c}9 \\
10\end{array}$ & Joint & $\begin{array}{l}0.6 \\
2.4\end{array}$ & 3 & 86.4 & 1 \\
\hline VII & $\begin{array}{c}0 \rightarrow 3 \rightarrow 9 \\
\rightarrow 7 \rightarrow 0\end{array}$ & $\begin{array}{l}3 \\
9 \\
\end{array}$ & Joint & $\begin{array}{l}2.1 \\
0.8 \\
\end{array}$ & 2.9 & 86.6 & 1 \\
\hline VIII & $\begin{array}{c}0 \rightarrow 7 \rightarrow 9 \\
\rightarrow 7 \rightarrow 0\end{array}$ & 9 & Out and back & 3 & 3 & 84.8 & 1 \\
\hline IX & $\begin{aligned} 0 & \rightarrow 7 \rightarrow 10 \\
& \rightarrow 7 \rightarrow 0\end{aligned}$ & 10 & Out and back & 6 & 6 & 69.4 & 2 \\
\hline $\mathrm{X}$ & $\begin{array}{c}0 \rightarrow 6 \rightarrow 8 \\
\rightarrow 5 \rightarrow 0\end{array}$ & $\begin{array}{l}6 \\
8 \\
5 \\
\end{array}$ & Joint & $\begin{array}{l}1.4 \\
1.2 \\
0.4 \\
\end{array}$ & 3 & 73 & 1 \\
\hline XI & $\begin{array}{c}0 \rightarrow 5 \rightarrow 6 \\
\rightarrow 7 \rightarrow 0\end{array}$ & $\begin{array}{l}5 \\
7\end{array}$ & Joint & $\begin{array}{c}0.2 \\
2\end{array}$ & 2.2 & 75.8 & 1 \\
\hline XII & $0 \rightarrow 5 \rightarrow 0$ & 5 & Out and back & 3 & 3 & 64.4 & 1 \\
\hline XIII & $0 \rightarrow 6 \rightarrow 0$ & 6 & Out and back & 3 & 3 & 61.4 & 1 \\
\hline XIV & $0 \rightarrow 7 \rightarrow 0$ & 7 & Out and back & 3 & 3 & 63.4 & 1 \\
\hline XV & $\begin{array}{c}0 \rightarrow 6 \rightarrow 8 \\
\rightarrow 6 \rightarrow 0\end{array}$ & 8 & Out and back & 6 & 6 & 69.6 & 2 \\
\hline
\end{tabular}

Calculated as the Dijkstra's Algorithm and C-W Savings Algorithm, 15 distribution routes are got, 6 of which utilize the joint distribution mode; the total distance is $2215.3 \mathrm{~km}$ through calculation and 28 refrigerating cars are needed.

Table 6. Distribution distance and number of vehicles in the original distribution mode

\begin{tabular}{cccc}
\hline Distribution site & Average daily demand/t & $\begin{array}{c}\text { Distribution distance per } \\
\text { vehicle/km }\end{array}$ & Number of vehicles \\
\hline 1 & 22.1 & 70.4 & 8 \\
2 & 15.3 & 108 & 6 \\
3 & 2.1 & 68.8 & 1 \\
4 & 2.6 & 107 & 1 \\
5 & 3.6 & 64.4 & 2 \\
6 & 4.4 & 61.4 & 2 \\
7 & 5 & 63.4 & 2 \\
8 & 7.2 & 76.4 & 3 \\
9 & 4.4 & 88.4 & 2 \\
10 & 8.4 & 73.6 & 3 \\
11 & 7.9 & 76.8 & 3 \\
\hline
\end{tabular}

According to Table 6, the total distance under the former distribution mode is $2622.6 \mathrm{~km}>2215.3 \mathrm{~km}$ and $33>28$ refrigerating cars are needed through calculation. From this, it can be found that distribution using the optimized distribution plan can save the total distribution distance for $407.3 \mathrm{~km}$ each day, reduce 5 distribution cars so that enhancing the distribution efficiency and reducing the distribution cost. Besides, because the cold-chain warehouse \& distribution center of Y Company is located in the surrounding area of Chengdu City while most distribution sites are located in the urban area, the breakthrough of the limitation that the traditional logistics distribution center is located in the center of the geographical location popularize the Dijkstra's Algorithm and C-W Savings Algorithm in the practical distribution route optimization.

\section{Conclusion}

Most companies have great randomness in terms of the distribution routes choice in logistics distribution so that the distribution cost is high and the distribution efficiency is low. This paper takes the cold-chain warehouse \& distribution center of Y Company as the example, uses Dijkstra's 
Algorithm and C-W Savings Algorithm to optimize the distribution routes and utilizes the MATLAB software to deal with the problem of calculation difficulties with many knots. The software of MATLAB is easy to handle with and the results are easy to understand. Through the case analysis, it can be found that the distribution plan after optimizing can enhance the car loading rate, reduce the distribution cost, enhance the distribution efficiency, and meanwhile it has great social benefit for energy conservation, emission reduction, cutting down the environmental pollution, lightening the transportation pressure. Therefore, Dijkstra's Algorithm and C-W Savings Algorithm can solve the unreasonable transportation problems of the logistics companies such as roundabout distribution and meanwhile provide support for the achievement of city joint distribution.

\section{References}

[1] Coyle, J.J., Bardi, E.J., Langley, C.J. (2002). The Management of Business Logistics: A Supply Chain Perspective ( $7^{\text {th }}$ ed.). Mason: South-Western.

[2] Dantzig, G.B., Ramser, J.H. (1959). The truck dispatching problem. Management Science, 6(1), 80-91.

[3] Lenstra, J.K., Kan, A.H.G.R. (1981). Complexity of vehicle routing and scheduling problems. Networks, 11(2), 221-227.

[4] Barceló, J., Grzybowska, H., Pardo, S. (2007). Vehicle routing and scheduling models, simulation and city logistics. Operations Research/Computer Science Interfaces Series, 38, 163-195.

[5] Taniguchi, E., Thompson, R.G., Yamada, T., and van Duin, R. (2001). City Logistics: Network Modelling and Intelligent Transport Systems. Oxford: Pergamon Press.

[6] Ghiani, G., Laporte, G., Musmanno, R. (2004). Introduction to Logistics Systems Planning and Control. Chichester: John Wiley \& Sons.

[7] Fisher, M.L., Jaikumar, R. (1981). A generalized assignment heuristic for vehicle routing. Networks, 11(2), 109-124.

[8] Clarke, G., Wright, J.W. (1964). Scheduling of vehicles from a central depot to a number of delivery points. Operations Research, 12(4), 568-581.

[9] Lin, S. (1965). Computer solutions of the traveling salesman problem. Bell System Technical Journal, 44(10), 2245-2269.

[10] Gaskell, T.J. (1967). Bases for vehicle fleet scheduling. OR, 18(3), 281-295.

[11] Christofides, N., Eilon, S. (1969). An algorithm for the vehicle-dispatching problem. OR, 20(3), 309-318.

[12] Dijkstra, E. W. (1959). A note on two problems in connexion with graphs. Numerische Mathematik, 1(1), 269-271. 